\title{
Crystalloid Coload vs Colloid Coload following Spinal Anesthesia for Elective Cesarean Delivery: The Effects on Maternal Central Venous Pressure
}

\author{
Umesh Sivanna
}

\begin{abstract}
Introduction: Spinal anesthesia is widely used in the management of uncomplicated cesarean section. Maternal hypotension is the commonest serious problem which decreases uterine blood flow causing fetal hypoxia, acidosis, and neonatal depression. Fluid administration before start of the surgery (preloading) with crystalloid is found to be ineffective due to rapid redistribution of fluids in various tissue spaces. A "coload" given at the time of spinal anesthesia may be more effective. Most studies have concentrated on noninvasive systolic blood pressure (SBP) measurements to evaluate the effect of such regimens. We used central venous pressure (CVP) measurement technique in parturients receiving rapid administration of crystalloid or colloid solution at the time of initiation of anesthesia (coload). We hypothesized that a colloid coload compared with a crystalloid coload would produce a larger sustained increase in volume and therefore reduce vasopressor requirements.
\end{abstract}

Materials and methods: We recruited healthy term women scheduled for elective cesarean delivery under spinal anesthesia for this randomized study. Baseline heart rate, baseline mean arterial blood pressure (MAP), and CVP were recorded. At the time of spinal injection, subjects were allocated to receive a rapid $1 \mathrm{~L}$ coload of either polymerized gelatin 3.5\% (Haemaccel) or Hartmann (crystalloid) solution. The primary outcome CVP was compared between groups, as were secondary outcomes: phenylephrine dose and maternal hemodynamics data.

Results: Maternal demographics, surgical times, and American Society of Anesthesiologists (ASA) were similar between groups. Baseline parameters were similar in all the three groups. Heart rate increased from the baseline in all the three groups; however, mean heart rate was highest in crystalloid group. Mean arterial blood pressure decreased in all the three groups from baseline; however, highest fall was recorded in crystalloid group. The incidence of hypotension was $66.66 \%$ in crystalloid group as compared with $36.66 \%$ in colloid group. Crystalloid group patients received $6.33 \pm 4.54 \mathrm{mg}$ of ephedrine as compared with $2.40 \pm 2.82 \mathrm{mg}$ in colloid group. Thus, the incidence of hypotension and ephedrine consumption was significantly higher in crystalloid group as compared with colloid group. We found statistically significant differences in the mean preoperative

\section{Associate Professor}

Department of Cardiovascular, Sri Jayadeva Institute of Cardiovascular Sciences and Research, Bengaluru, Karnataka India

Corresponding Author: Umesh Sivanna, Associate Professor Department of Cardiovascular, Sri Jayadeva Institute of Cardiovascular Sciences and Research, Bengaluru, Karnataka India, Phone: +919945603456, e-mail: umeshbushi@yahoo.co.in
CVP reading $(p<0.05)$ between the two groups, the mean CVP reading in crystalloid group being slightly lower. With preloading, similar CVP readings were obtained in both groups. The fall in CVP during subarachnoid blockade was also not significant. The CVP began to fall with the establishment of the block until the delivery of the baby after which it was found to rise. The predelivery CVP was significantly lower than preoperative CVP in both groups - the fall being significantly more in crystalloid group.

Conclusion: In our study, the results showed statistically significant decrease in volume requirement, when colloid coload is used than crystalloid coload using CVP monitor as a guide. Colloid coloading is effective and superior to crystalloid coloading for prevention of maternal hypotension in cesarean section.

Keywords: Central venous pressure, Colloids, Coloading, Crystalloids.

How to cite this article: Sivanna U. Crystalloid Coload vs Colloid Coload following Spinal Anesthesia for Elective Cesarean Delivery: The Effects on Maternal Central Venous Pressure. J Med Sci 2017;3(4):95-101.

\section{Source of support: Nil}

Conflict of interest: None

\section{INTRODUCTION}

Spinal anesthesia is widely used in the management of uncomplicated cesarean section. Hypotension is the commonest serious problem which decreases uterine blood flow causing fetal hypoxia, acidosis, and neonatal depression. Prevention of hypotension is more desirable than correction, as without preventive measures the incidence of hypotension can be as high as $90 \% .{ }^{1}$ Additional measures were tried with varying success, such as intravenous (IV) infusion of 5\% albumin in 5\% dextrose in Ringer's lactate, $15 \mathrm{~mL} / \mathrm{kg}^{2}{ }^{2} \mathrm{IV}$ boluses of ephedrine, ${ }^{3}$ IV infusion of dopamine, ${ }^{4}$ and IV ephedrine infusion. ${ }^{5,8}$ Fluid coloading appears to be more physiological and rational approach as the maximal effect can be achieved at the time of onset of the block. ${ }^{6}$ Recently, few studies have been conducted which indicate that coloading may be equally effective as preloading with colloid. ${ }^{7,8}$

Central venous pressure monitoring reflects the volume load in the circulatory system. Therefore, the changes in hemodynamic status occurring in these patients after subarachnoid block can be optimally assessed by monitoring CVP. 
In the present study, CVP monitoring was used to evaluate the effects of coloading solutions, such as colloids or crystalloids in the prevention of hypotension following subarachnoid block for elective cesarean section. The primary outcome of CVP was compared between groups, as were secondary outcomes: incidence of hypotension, phenylephrine dose, and maternal hemodynamic data.

\section{MATERIALS AND METHODS}

This study was conducted in the Department of Anesthesiology, M.S. Ramaiah Medical College Teaching Hospital, Bengaluru, India. Total 60 parturients admitted in our hospital for elective cesarean section under spinal anesthesia belonging to ASA-I and ASA-II under the age group of 20 to 35 years constituted the patient population for the study.

\section{Group A-Colloid Group}

It comprised 30 patients receiving $15 \mathrm{~mL} / \mathrm{kg}$ of polymerized gelatin (3.5\%) (Haemaccel) for coloading prior to spinal anesthesia.

\section{Group B-Crystalloid Group}

It comprised 30 patients receiving $15 \mathrm{~mL} / \mathrm{kg}$ of lactated Ringer's for coloading prior to spinal anesthesia.

On admission, a full medical, obstetric, and anesthetic history was taken, followed by detailed general, physical, and obstetric examination. Basic investigations like hemogram, random blood sugar, blood grouping and typing, and urine examination for albumin, sugar, and microorganisms were done.

Normotensive parturient belonging to ASA-I and ASA-II aged between 20 and 35 years undergoing elective cesarean section under spinal anesthesia were included in the study. Patients unwilling for study procedure, patients coming for emergency cesarean section, patients with pregnancy-induced hypertension, history of cardiac and chronic respiratory diseases, and patients with history of bleeding disorders were excluded from the study.

The procedure was explained to the patients and to a reliable relative or attendant. Informed consent was obtained from all the patients.

\section{POSITION OF THE PATIENT}

Patient was positioned with left lateral tilt achieved by a $10 \mathrm{~cm}$ wedge under the right buttock. All the IV lines were set up using an 18G IV cannula on the left forearm, and appropriate fluid (crystalloid or colloid) was started.

Under local anesthesia, central venous cannulations were done via internal jugular vein using Abbocath with
Seldinger's technique with all aseptic precautions. The catheter was connected to the manometer.

In our study, the mid-right atrial level at the level of the anterior axillary line was chosen as zero point, as changes in the patient position has minimal effect on CVP readings.

Baseline readings of pulse, mean blood pressure (BP), and CVP were recorded. The randomization was done using envelope method. The patients were randomly given either lactated Ringer's solution or gelatin 3.5\% as coloading solution. The volume of crystalloid or colloid required for this preloading was noted. Pulse, MAP, and CVP were noted after preloading.

The patients were turned to the left lateral semi-flexed position and lumbar puncture was done using $22 \mathrm{G}$ or $23 \mathrm{G}$ spinal needle. After clear and free flow of cerebrospinal fluid was obtained, 50 to $65 \mathrm{mg}$ (1-1.2 mL) of hyperbaric xylocaine $5 \%$ was injected. The patient was immediately repositioned supine with $10 \mathrm{~cm}$ wedge under the right buttock.

Pulse, BP, and CVP readings were recorded during spinal anesthesia and at 1-minute intervals thereafter. Oxygen (100\%) was administered via facemask till delivery of the baby. Sensory level of spinal blockade was assessed by pinprick 5 minutes later. After extraction of the fetus, oxytocin infusion (10 units in $500 \mathrm{~mL}$ ) of crystalloid was started. Patients were sedated with diazepam (10 mg IV) or midazolam (1-2 mg IV).

Maintenance of fluids was continued intraoperatively as required. Blood pressure and CVP were measured every 10 minutes thereafter.

\section{OBSERVATION AND RESULTS}

Both groups were comparable with respective age and weight (Table 1).

The mean preoperative heart rate (Tables 2 and 3) was comparable in both groups $(\mathrm{p}>0.5)$. After preloading, there was an increase in the heart rate of crystalloid group, but not much in the colloid group, the increase in the heart rate in the crystalloid group being higher than in the colloid group. This trend of heart rate continued throughout the intraoperative period until delivery after which it began to fall. The increase in the heart rate from preoperative to predelivery values was statistically significant in both groups-the rise in crystalloid group being significantly higher than the colloid group. There

Table 1: Age and weight distribution

\begin{tabular}{lll}
\hline & Colloid group & Crystalloid group \\
\hline Age & 27.4 & 25.4 \\
Weight & 61.5 & 58.5 \\
Height & $158.35+5.45$ & $157.45+4.92$ \\
Total & 30 patients & 30 patients \\
\hline
\end{tabular}


Crystalloid Coload vs Colloid Coload following Spinal Anesthesia

was no significant difference in the heart rate during the delivery and in the postdelivery period between the two groups.

The mean preoperative BPs in both groups (Tables 4 and 5) were comparable $(p>0.05)$. With coloading, the $\mathrm{BP}$ increased significantly in both groups, the increase being significantly higher in the colloid group. With the administration of spinal anesthesia, the BP fell significantly in both the groups, the fall being much higher in the crystalloid group. In the colloid group, after the delivery of the baby the BP raised to reach and in most cases exceeded preoperative BP. The increase in BP after delivery was less and postdelivery did not reach the preoperative values in crystalloid groups.

There are statistically significant differences in the mean preoperative CVP reading $(\mathrm{p}<0.05)$ between the two groups (Table 6), the mean CVP reading in crystalloid group being slightly lower (Table 6). With preloading, similar CVP readings were obtained in both groups. The preoperative CVP and preload CVP obtained in the two groups was not significant. The fall in CVP during

Table 2: Heart rate response

\begin{tabular}{llll}
\hline & Crystalloid group & Colloid group & $p$-value \\
\hline Baseline & $87.04 \pm 4.7$ & $87.68 \pm 5.27$ & NS \\
Coload & $89.36 \pm 5.21$ & $88.92 \pm 5.38$ & NS \\
Spinal anesthesia & $92.72 \pm 5.01$ & $89.52 \pm 5.52$ & $<0.5$ \\
Predelivery & $104.8 \pm 8.45$ & $98.8 \pm 5.31$ & $<0.01$ \\
Delivery & $102 \pm 6.11$ & $100.48 \pm 4.24$ & NS \\
Postdelivery & $90.4 \pm 4.63$ & $92.4 \pm 4.74$ & NS \\
\hline
\end{tabular}

NS: Not significant

Table 3: Heart rate response difference between groups and different intervals

\begin{tabular}{lllll}
\hline & $P O-P L$ & $p$-value & $P O-P r D$ & $p$-value \\
\hline Colloid group & $2.37 \pm 1.83$ & $<0.001$ & $11.76 \pm 3.5$ & $<0.001$ \\
Crystalloid group & $0.26 \pm 1.38$ & & $17.4 \pm 6.74$ & \\
\hline PO: Baseline; $\mathrm{PL}$ : Coload; PrD: Predelivery &
\end{tabular}

PO: Baseline; PL: Coload; PrD: Predelivery

Table 4: Mean BP response

\begin{tabular}{llll}
\hline & Colloid group & Crystalloid group & $p$-value \\
\hline Baseline & $85.09 \pm 6.24$ & $84.16 \pm 7.31$ & $\mathrm{NS}$ \\
Coload & $89.69 \pm 4.96$ & $86.33 \pm 5.80$ & $<0.01$ \\
Spinal anesthesia & $82.56 \pm 7.66$ & $78.76 \pm 6.4$ & $<0.001$ \\
Predelivery & $80.66 \pm 8.73$ & $77.56 \pm 5.59$ & $<0.001$ \\
Delivery & $82.97 \pm 8.69$ & $79.45 \pm 6.14$ & $<0.001$ \\
Postdelivery & $84.02 \pm 2.94$ & $80.62 \pm 5.68$ & $<0.001$ \\
\hline
\end{tabular}

NS: Not significant

Table 5: Mean BP response

\begin{tabular}{lllll}
\hline & $P O-P L$ & $p$-value & $P O-P r D$ & $p$-value \\
\hline Colloid group & $4.6+1.28$ & $<0.001$ & $4.43+2.45$ & $<0.001$ \\
Crystalloid group & $2.17 \pm 1.51$ & & $6.60 \pm 1.72$ & \\
\hline PO: Baseline; PL: Coload; PrD: Predelivery & &
\end{tabular}

Table 6: Central venous response

\begin{tabular}{lllc}
\hline & Colloid group & Crystalloid group & $p$-value \\
\hline Baseline & $6 \pm 0.89$ & $5.44 \pm 0.98$ & $<0.05$ \\
Coload & $9.8 \pm 0.37$ & $9.72 \pm 0.67$ & $\mathrm{NS}$ \\
Spinal anesthesia & $8.72 \pm 0.76$ & $8.88 \pm 0.71$ & $\mathrm{NS}$ \\
Predelivery & $5.56 \pm 1.24$ & $4.68 \pm 1.085$ & $<0.01$ \\
Delivery & $7.7 \pm 0.99$ & $6.68 \pm 1.009$ & $<0.001$ \\
Postdelivery & $9.24 \pm 1.21$ & $7.48 \pm 0.85$ & $<0.001$ \\
\hline
\end{tabular}

NS: Not significant

Table 7: Fluid input

\begin{tabular}{lll}
\hline Groups & Fluids load coload & Intraoperative fluids \\
\hline Colloid group & $546 \pm 42 \mathrm{~mL}$ & $298 \pm 38.7 \mathrm{~mL}$ \\
Crystalloid group & $562 \pm 63 \mathrm{~mL}$ & $928 \pm 107 \mathrm{~mL}$ \\
\hline
\end{tabular}

Table 8: Complications

\begin{tabular}{lll}
\hline Side effects & Crystalloid group & Colloid group \\
\hline PONV & 9 & 2 \\
Hypotension & $9(60 \%)$ & $6(40 \%)$ \\
\hline
\end{tabular}

PONV: Postoperative nausea and vomiting

subarachnoid blockade was also not significant. Central venous pressure began to fall with the establishment of the block until the delivery of the baby after which it was found to rise. The predelivery CVP was significantly lower than preoperative CVP in both groups-the fall being significantly more in crystalloid group. The sensory level of T6 was obtained in 54\% of patients and T7 was obtained in $46 \%$ of patients. The levels were comparable in the two groups.

The crystalloid group (Table 7) received more fluids than the colloid groups both for coloading and during the intraoperative period. The total crystalloid requirement was approximately three times of the colloid requirement.

The only complications encountered (Table 8) in this study were nausea and vomiting. Nine patients in crystalloid group complained of nausea as against two in colloid group. This was associated with hypotension in all cases and subsided with correction of the same. The number of bolus doses and total dose of ephedrine (Graph 1) administered were more in crystalloid group compared with colloid group.

\section{DISCUSSION}

In clinical practice, CVP can be used to detect changes in blood volume, if a stable baseline is shown.

It provides a useful estimate of right ventricular function and gives a reliable measure of the balance between systemic venous return and right ventricular performance. 


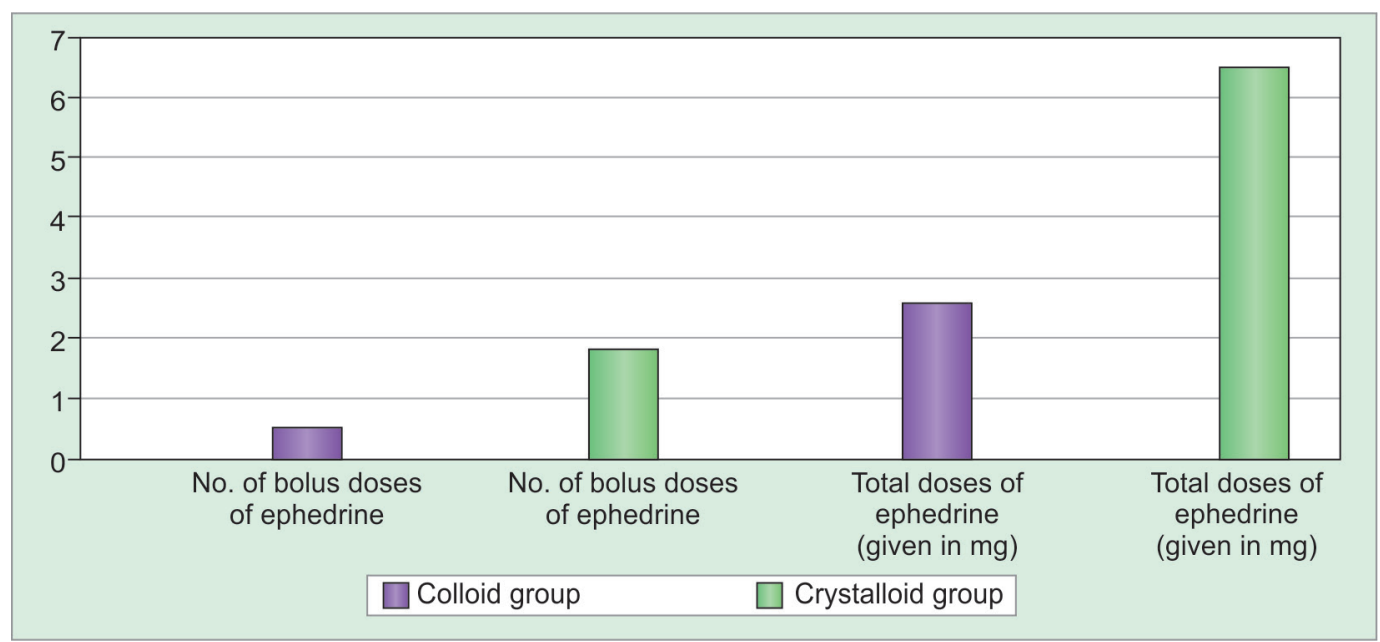

Graph 1: Number of bolus doses and total doses of ephedrine given in the two groups

Venous pressure was first measured by Stephen Hales. ${ }^{9}$ It was measured in humans by Frey in 1902 and was used clinically in 1910. Central venous pressure began to be used with increased frequency from 1963 to 1964 onward.

In the obstetric patient, regional technique for elective cesarean section was associated with high incidence of hypotension, compounded by supine hypotension syndrome and aortocaval compression. Hence, various techniques to prevent this complication were tried.

- Position: Placing the patient in the left lateral position, hip elevation, and uterine displacers.

- Improvement of venous return by application of Esmarch's bandage ${ }^{10}$ and inflatable splints ${ }^{11}$ to the lower extremities.

- Vasopressors like methoxamine ${ }^{12}$ ephedrine given intramuscular, ${ }^{13}$ as intravenous bolus, ${ }^{3}$ and intravenous infusion, ${ }^{5}$ dopamine infusion, ${ }^{4}$ and phenylephrine ${ }^{14}$ were tried with varying success.

- Preloading the patients with crystalloids or colloids like albumin, ${ }^{2}$ Hetastarch, ${ }^{15,16}$ Dextran, ${ }^{17}$ and polymerized gelatin before spinal anesthesia was found to be effective in reducing the incidence of hypotension.

This study was conducted on 60 patients who came for elective cesarean section under spinal anesthesia. Group I comprised 30 patients who received crystalloid (Ringer's lactate) and group II comprised 30 patients who received colloid (gelatin $3.5 \%$ ) as preload.

The following parameters were compared:

- Heart rate response to spinal anesthesia and delivery

- BP response and incidence of hypotension

- CVP changes

- Volume of fluid infused during coload and intraoperatively

- Sensory level of subarachnoid blockade

- Incidence of hypotension and requirement of vasopressor

- Side effects.
The two groups were comparable with respect to age and weight.

Most patients in the study $(60 \%)$ were second gravida, the rest were third gravida $(25 \%)$ and fourth gravida $(12 \%)$. The indication for cesarean section in most cases was previous cesarean section, though others were taken up for abnormal lie position or bad obstetric history. The crystalloid group had more gravida $2(24 / 30)$ when compared with colloid group (14/30).

\section{Heart Rate Response}

The heart rate was monitored throughout, but pulse rates at specific times were noted and compared. The baseline heart rates were comparable in both the groups. After preloading the heart rate increased significantly from baseline in both groups and was statistically not significant. This observation is consistent with that of Mathru et $\mathrm{al}^{2}$ and Rout et $\mathrm{al}^{18}$ who reported increase in the heart rate on preloading with crystalloid, similar to report of Wollman and Marx. ${ }^{19}$

During induction of anesthesia, the heart rate increased in both the groups, the rise being significantly higher throughout the procedure in the crystalloid group. This correlates well with studies by Mathru et al, ${ }^{2}$ Rout et $\mathrm{al}^{18,20}$ and Riley et al, ${ }^{21}$ who reported similar increase in the heart rate after induction of anesthesia. The highest heart rates were seen 2 to 4 minutes after spinal anesthesia and during extraction of the baby. This observation was similar to reports by Riley et al. ${ }^{21}$

\section{Blood Pressure Response}

Both SBP and diastolic blood pressure were measured before preload, after preload, during spinal anesthesia, and at 1-minute intervals, thereafter till extraction of the baby following which BP was measured at 10-minute intervals. The mean preoperative SBPs were comparable 
in the two groups. With coloading, the arterial pressure (SAP) increased significantly in both groups $(p<0.001$ for crystalloid, $\mathrm{p}<0.001$ for colloid). This is similar to reports by Mathru et al, ${ }^{2}$ Riley et al, ${ }^{21}$ and Karinen et al. ${ }^{22}$ After spinal anesthesia, the SAP fell in both groups. The degree of fall was significant, higher in crystalloid group (18.88 \pm $7.58 \mathrm{~mm} \mathrm{Hg}$ in crystalloid group vs $9.6 \pm 6.02 \mathrm{~mm} \mathrm{Hg}$ in colloid group, $\mathrm{p}<0.001)$. The fall in MAP was sudden and was noted between 4 and 6 minutes after anesthesia in the crystalloid group. Gradual fall in MAP was noted around 6 to 8 minutes thereafter. These findings corelate well with findings by Riley et $\mathrm{al}^{21}$ and Karinen et $\mathrm{al}^{22}$ The fall in arterial pressure after spinal anesthesia was a universal finding in all studies. The degree and duration of fall varied between studies. Wollman and Marx ${ }^{19}$ reported significant fall in the MAP in nonhydrated patients, but not in patients hydrated with $1 \mathrm{~L}$ of crystalloids. Clark et $\mathrm{al}^{7}$ reported incidence of hypotension as $57 \%$ with fluid loading only and $52.8 \%$ with fluid loading and uterine displacement. Mathru et $\mathrm{al}^{2}$ reported significant fall in MAP, 3 minutes after spinal anesthesia in patients preloaded with D5 Ringer's lactate but not in patients receiving $5 \%$ albumin as preload. Rout et al ${ }^{18}$ reported an initial increase in SAP at 1 minute followed by significant fall at 4 to 5 minutes of postspinal, in patients preloaded with crystalloid over 20 or 10 minutes before spinal anesthesia. Rout et $\mathrm{al}^{18}$ reported significant fall in mean SAP at 2 to 6 minutes after spinal anesthesia in both groups. Riley et $\mathrm{al}^{22}$ reported a higher fall in SAP in crystalloid group receiving Ringer's lactate with respect to colloid receiving haemaccel (3.5\%). Vercauteren et $\mathrm{al}^{16}$ reported the incidence of severe hypotension (SAP $<90 \mathrm{~mm} \mathrm{Hg}$ ) 1:3 in patients receiving Ringer's lactate with modified gelatin and 6\% Hetastarch vs 1:10 in patients receiving Ringer's lactate with $6 \%$ Hetastarch.

In a study by Dahlgren et $\mathrm{al}^{23}$ higher frequency of hypotension in crystalloid preload group was noted compared with colloid preload group. They opined that colloid preloading is superior to crystalloid in reducing the severity and incidence of hypotension.

Our results are similar to those of Teoh and $\mathrm{Sia}^{24}$ and Siddik-Sayyid et al, ${ }^{25}$ who observed that the incidence of hypotension and vasopressor requirement was similar in the groups receiving colloid preload and coload. Riaz et $\mathrm{al}^{26}$ showed that preloading with colloids is more effective than crystalloids. Mercier et $\mathrm{al}^{4}$ showed that loading fluid (coloading) at the time of administering the intrathecal local anesthetic may be a physiologically more appropriate and better approach as the maximal effect of coloading can be achieved during the time of the block. Banerjee et $\mathrm{al}^{6}{ }^{6}$ in their meta-analysis, showed that the incidence of hypotension in the coload group was $59.3 \%$ compared with $62.4 \%$ in the preload group.

A Study done by Wollman SB and Marx GF et.al for prevention of hypotension of spinal anesthesia in parturient by acute hydration found that those patients who underwent caesarean section under spinal block had sensory level at T2-T6, had no significant arterial hypotension but central venous pressures depressed which responded to infusion of $1000 \mathrm{~m} 1$ of $5 \%$ dextrose in lactated Ringer's solutions. Neonates of mothers in whom hypotension was prevented had significantly shorter "times to sustained respiration". 27

Early intervention with small IV doses of ephedrine 3-6 mg or methoxamine 1-2 mg provides a better control than the large IM doses given before block. Ephedrine is the probably the most useful in terms of safety and efficacy but a drug with predominantly alpha agonist activity. $^{28}$

There are various methods for prevention and treatment of hypotension during central neural blockade. McCrae AF and Wildsmith JA et $\mathrm{al}^{29}$ in their study showed:

- Mechanical methods like esmarch bandages, inflatable full length leg splints, adopting left lateral tilt with a wedge under the buttock.

- Volume loading.

- Use of vasopressors.

Thus, our study indicates that coloading with colloids is an effective method for prevention of hypotension as compared with crystalloids. Limitation of the study being adverse effects of colloids on coagulation were not studied. Clinically, we looked for oozing or excessive bleeding. The reason being, we were using colloids very much within the recommended dosages and it is said that colloids interfere with coagulation mechanism when used in very high doses.

\section{Central Venous Pressure Changes}

The CVP was measured at the following intervals before preload, after preload, during spinal anesthesia, at 1-minute interval till extraction of baby and 10-minute intervals thereafter.

There was a statistically significant difference in the mean CVP between two groups-the CVP in the crystalloid group being slightly lower $\left(5.4 \pm 0.98 \mathrm{~cm} \mathrm{H}_{2} \mathrm{O}\right.$ in the crystalloid group vs $6 \pm 0.89 \mathrm{~cm}$ of $\mathrm{H}_{2} \mathrm{O}$ in the colloid group). Preloading was done to increase the CVP from this baseline level to 8 to $10 \mathrm{~cm} \mathrm{H}_{2} \mathrm{O}$ using lactated Ringer's solutions in the crystalloid group and 3.5\% gelatin in colloid group. The mean CVP after preloading was comparable in the two groups $(9.8 \pm 0.37$ in the colloid group vs $9.72 \pm 0.67$ in crystalloid group). Central venous 
pressure remained within normal limits. Preloading was not associated with any signs of volume overload in any of these study subjects.

The CVP began to fall with the establishment of subarachnoid blockade and continued to fall till extraction of fetus. The fall in CVP was more abrupt and more severe in crystalloid group. In colloid group, the fall was gradual and less severe. Fall in CVP tended to precede the fall in SAP. The CVP fell to baseline values or below about 2 to 5 minutes postspinal in the crystalloid group. It then increased slowly, peaking during extraction, and postextraction, the CVP never exceeded preload values, in the crystalloid group.

These findings parallel reports by other authorsWollman and Marx ${ }^{19}$ reported significant increase in CVP after preload with crystalloid followed by fall with subarachnoid block. Fall was more in nonhydrated group. Following delivery, the CVP did not vary significantly between nonhydrated and hydrated groups.

Rout et $\mathrm{al}^{18}$ and Riley et $\mathrm{al}^{21}$ reported an increase in the CVP by $11.9 \mathrm{~cm}$ in patients receiving crystalloid preload over 10 minutes and by $7.3 \mathrm{~cm}$ in patients preloaded over 20 minutes. The CVP fell rapidly following spinal anesthesia returning toward baseline but increase after extraction. The CVP in the colloid group followed a similar course but was more gradual. The CVP increased, peaking postdelivery equal to or to exceed the preload values.

Karinen et $\mathrm{al}^{22}$ reported similar CVP changes in normotensive patients and patients with preeclampsia. ${ }^{16}$

\section{Sensory Level of Subarachnoid Blockade}

A sensory level of T6 as assessed by pin prick 5 minutes postspinal was obtained in $54 \%$ of patients. T7 was obtained in $46 \%$ of patients. These levels were similar to that obtained by Mathru et al. ${ }^{2}$ Other studies by Wollman and Marx $^{19}$ (T2-T5) and Rout et al ${ }^{18}$ (T3-T4) reported much higher levels of blockade. The incidence of hypotension was approximately similar in this study and others. Vasopressors were given (6-12 mg ephedrine) to bring up SAP in this study.

\section{Apgar Scores}

The Apgar scores at 1 and 5 minute(s) were comparable in both groups. No baby had Apgar scores below 7 and 10 at 1 and 5 minute(s) respectively.

No serious complications were encountered during the placement of central venous line. Intraoperatively, nine patients in the crystalloid group and two patients in colloid group complained of nausea. It was associated with hypotension in every case. One patient in crystalloid group had vomiting which subsided once hypotension was corrected. Hypotension was corrected by IV fluid bolus and oxygen supplementation.

\section{Fluid Infused}

The volume of fluid (crystalloid or colloid) required to raise the CVP to 8 to $10 \mathrm{~cm}$ from baseline was calculated by dividing the preloading volume with weight of the patients.

The mean preload volume required was $9.5 \mathrm{~mL} / \mathrm{kg}$ body weight for colloid (3.5\% gelatin) and $30 \mathrm{~mL} / \mathrm{kg}$ for crystalloid (lactated Ringer's solution). Similar studies have shown that volume of crystalloid required to replace the blood volume during hypovolemic states was about 3 to 4 times greater than the volume of $5 \%$ albumin or blood needed to restore the blood volume. The volume obtained in our study corresponds with this findingthree times the volume of colloid was required to increase the CVP to similar levels using crystalloid. Even with the use of large volume of crystalloid, the incidence of hypotension was high. This is probably due to the extravascular redistribution of crystalloid which does not maintain the intra-vascular volume long enough to prevent hypotension after spinal anesthesia. Gelatin (3.5\%) therefore confers definite advantages over lactated Ringer's solutions for coloading. But gelatin is much costlier than lactated Ringer's solution. It may affect coagulation system and might produce hypersensitivity reactions.

\section{CONCLUSION}

It is well known that prolonged or severe maternal hypotension can cause serious adverse fetal and neonatal effects. Spinal anesthesia can cause profound hypotension and bradycardia resulting in occasional fatalities.

Because of paucity of clinical trials, we embarked on comparison of crystalloids and colloids coloading with CVP as a guide and monitoring for adequacy of loading.

In our study, the results showed statistically significant decrease in volume requirement when colloid coload is used than crystalloid coload.

In patients undergoing elective cesarean delivery under spinal anesthesia, we can conclude that the timing of fluid loading does not significantly influence the incidence of hypotension. This is true for both colloid and crystalloid loading. Hence, it is unnecessary to delay surgery in order to deliver a load of fluid. Regardless of the fluid loading strategy, vasopressors may be required for therapeutic purpose in some proportion of patients.

\section{REFERENCES}

1. Clark RB, Burner JA 3rd. Dopamine for the treatment of spinal hypotension associated with caesarean section. Anesthesiology $1980 \mathrm{Dec} ; 53(6): 514-517$. 
2. Mathru M, Rao TL, Kartha RK, Shanmugham M, Jacobs HK. Intravenous albumin administration for prevention of spinal hypotension during cesarean section. Anesth Analg 1980 Sep;59(9):655-658.

3. Shnider SM, de Lorimier AA, Holl JW, Chapler FK, Morishima HO. Vasopressors in obstretics. Am J Obstet Gynecol 1968 Dec;102(7):911-919.

4. Mercier FJ, Bonnet MP, De la Dorie A, Moufouki M, Banu F, Hanaf A, Edouard D, Roger-Christoph S. Spinal anaesthesia for caesarean section: fluid loading, vasopressors and hypotension. Ann Fr Anaesth Reanim 2007 Jul-Aug;26(7-8): 688-693.

5. Carvalho B, Mercier FJ, Riley ET, Brummel C, Cohen SE. Hetastarch co-loading is as effective as Preloading for the prevention of hypotension following spinal anaesthesia for caesarean delivery. Int J Obstet Anaesth 2009 Apr;18(2):150-155.

6. Banerjee A, Stocche RM, Angle P, Halpern SH. Preload or coload for spinal anaesthesia for elective Caesarean delivery: a meta-analysis. Can J Anaesth 2010 Jan;57(1):24-31.

7. Clark RB, Thompson DS, Thompson CH. Prevention of spinal hypotension associated with cesarean section. Anesthesiology 1976 Dec;45(6):670-674.

8. Kang YG, Abouleish E, Caritis S. Propylactic intravenous ephedrine infusing during spinal anesthesia for cesarean section. Anesth Analg 1982 Oct;61(10):839-842.

9. Hug, CC. CVP monitoring. In: Miller RD, editor. Anesthesia. 2nd ed. Vol. 1. New York: Churchill Livingstone; 1986. pp. 438-448.

10. Bhagwanjee S, Rocke DA, Rout CC, Koovarjee RV, Brijball R. Prevention of hypotension following spinal anaesthesia for elective caesarean section by wrapping of legs. Br J Anaesth 1990 Dec;65(6):819-822.

11. Goudie TA, Winter AW, Ferguson DJ. Lower limb compression using inflatable splints to prevent hypotension during spinal anaesthesia for caesarean section. Acta Anaesthesiol Scand 1988 Oct;32(7):541-544.

12. Ralston DH, Shnider SM, DeLorimier AA. Effects of equipotent ephedrine, metaraminol on uterine blood flow in pregnancy. Anesthesiology 1974 Apr;40(4):354-370.

13. Gutsche BB. Prophylatic ephedrine proceeding spinal analgesia for cesarean section. Anesthesiology 1976;45: 462-465.

14. Weiner, N. Nor epinephrine, epinephrine. In: Goodman LS, Gilman A, Gilman AG, editors. Goodman and Gilman's pharmacological basis for therapeutics. 7th ed. New York: Macmillan; 1985. pp. 145-180.

15. Barka AS, Taha SK, Ghabach MB, Sibaii AA, Nader AM. Intravascular administration of polymerized gelatin Vs isotonic saline for prevention of spinal induced hypotension. Anesth Analg 1994 Feb;78(2):301-305.

16. Vercauteren MP,Hoffman V,Coppejans HC, VanSteenberge AL, Adriaensen HA. Hydroxyethylstarch compared with modified gelatin as volume preload before spinal anaesthesia for caesarean section. Br J Anaesth 1990;76:731-733.

17. Wennberg E, Frid I, Haljamäe H, Wennergren M, Kjellmer I. Comparison of Ringer's acetate with 3\% dextran for volume loading. Br J Anesth 1990 Nov;65(5):654-660.

18. Rout CC, Akoojee SS, Rocke DA, Gouws E. Rapid administration of crystalloid preload does not decrease the incidence of hypotension after spinal anaesthesia for caesarean section. Br J Anaesth 1992 Apr;68(4):394-397.

19. Wollman SB, Marx GF. Acute hydration for prevention of hypotension of spinal anesthesia in parturient. Anesthesiology 1968 Mar-Apr;29(2):374-380.

20. Rout CC, Rocke DA, Levin J, Gouws E, Reddy D. A reevaluation of the role of crystalloid preload in the prevention of hypotension associated with spinal anesthesia for elective cesarean section. Anesthesiology 1993 Aug;79(2): 262-269.

21. Riley ET, Cohen SE, Rubenstein AJ, Flanagan B. Prevention of hypotension after spinal anaesthesia for cesarean section: $6 \%$ heptastich versus lactated ringer's solution. Anesth Analg 1995 Oct; 81(4):838-842.

22. Karinen J, Räsänen J, Alahuhta S, Jouppila R, Jouppila P. Effect of crystalloid and colloid on uteroplacental and maternal hemodynamics. Br J Anaesth 1995 Nov;75(5):531-535.

23. Dahlgren G, Granath F, Pregner K, Rösblad PG, Wessel H, Irestedt L. Colloid vs. crystalloid Preloading to prevent maternal hypotension during spinal anaesthesia for elective caesarean section. Acta Anaesthesiol Scand 2005 Sep;49(8): 1200-1206.

24. Teoh WH, Sia AT. Colloid preload versus coload for spinal anaesthesia for caesarean delivery: the effects on maternal cardiac output. Anaesth Analg 2009 May;108(5):1592-1598

25. Siddik-Sayyid SM, Nasr VG, Taha SK, Zbeide RA, Shehade JM, Al Alami AA, Mokadem FH, Abdallah FW, Baraka AS, Aouad MT. A Randomized trial comparing colloid preload to coload during spinal anaesthesia for elective caesarean delivery. Anaesth Analg 2009 Oct;109(4):1219-1224.

26. Riaz A, Munzar Z. Preloading before spinal anaesthesia for Caesarean section. A comparison between colloid and crystalloid preload. Anaesth Pain Intens Care 2006;10(1):9-12.

27. Bridenbaugh, P0.; Kennedy, WF. Spinal, subarachanoid neural blockade. In: Cousins MJ, Bridenbaugh PO, ediors. Neural blockade in clinical anesthesia and management of pain. Philadelphia (PA): Lippincott Williams \& Wilkins; 1998. pp. 168-171.

28. Cheek, TG.; Gutsche, BB. Maternal physiological alterations during pregnancy. In: Shnider SM, Levinson G, editors. Anesthesia for obstetrics. 3rd ed. Baltimore (MD): Williams and Wilkins; 1993. pp. 3-17.

29. McCrae AF, Wildsmith JA. Preventing and treatment of hypotension during central neural block. Br J Anesth 1993 Jun;70(6):672-680. 